\title{
Angiogenic, hyperpermeability and vasodilator network in utero-placental units along pregnancy in the guinea-pig (Cavia porcellus) \\ Gloria Valdés ${ }^{1,2}$, Rafaela Erices², Cecilia Chacón² and Jenny Corthorn*1,2
}

\author{
Address: ${ }^{1}$ Departamento de Nefrología, Escuela de Medicina, Pontificia Universidad Católica de Chile, Marcoleta 391, 8330024 Santiago, Chile \\ and ${ }^{2}$ Centro de Investigaciones Médicas, Escuela de Medicina, Pontificia Universidad Católica de Chile, Santiago, Chile \\ Email: Gloria Valdés - gvaldes@med.puc.cl; Rafaela Erices - rafaela.erices@gmail.com; Cecilia Chacón - chacon_cecilia@hotmail.com; \\ Jenny Corthorn* - jcorthor@med.puc.cl \\ * Corresponding author
}

Published: 27 March 2008

Reproductive Biology and Endocrinology 2008, 6:13 doi:10.1186/1477-7827-6-13

This article is available from: http://www.rbej.com/content/6/1/13

(C) 2008 Valdés et al; licensee BioMed Central Ltd.

This is an Open Access article distributed under the terms of the Creative Commons Attribution License (http://creativecommons.org/licenses/by/2.0), which permits unrestricted use, distribution, and reproduction in any medium, provided the original work is properly cited.
Received: 26 November 2007

Accepted: 27 March 2008

\begin{abstract}
Background: The angiogenic and invasive properties of the cytotrophoblast are crucial to provide an adequate area for feto-maternal exchange. The present study aimed at identifying the localization of interrelated angiogenic, hyperpermeability and vasodilator factors in the feto-maternal interface in pregnant guinea-pigs.

Methods: Utero-placental units were collected from early to term pregnancy. VEGF, Flt-I, KDR, B2R and eNOS were analyzed by immunohistochemistry, and the intensity of the signals in placenta and syncytial streamers was digitally analysed. Flt I and eNOS content of placental homogenates was determined by western blotting. Statistical analysis used one-way analysis of variance and Tukey's Multiple Comparison post-hoc test.

Results: In the subplacenta, placental interlobium and labyrinth VEGF, Flt-I, KDR, B2R and eNOS were expressed in all stages of pregnancy. Syncytial streamers in all stages of gestation, and cytotrophoblasts surrounding myometrial arteries in early and mid pregnancy - and replacing the smooth muscle at term displayed immunoreactivity for VEGF, FIt-I, KDR, eNOS and B2R. In partly disrupted mesometrial arteries in late pregnancy cytotrophoblasts and endothelial cells expressed VEGF, FIt-I, KDR, B2R and eNOS. Sections incubated in absence of the first antibody, or in presence of rabbit IgG fraction and mouse IgG serum, yielded no staining. According to the digital analysis, Flt- I increased in the placental interlobium in days 40 and 60 as compared to day $20(P=0.016)$, and in the labyrinth in day 60 as compared to days 20 and $40(P=0.026)$, while the signals for VEGF, KDR, B2R, and eNOS showed no variations along pregnancy. In syncytial streamers the intensity of VEGF immunoreactivity was increased in day 40 in comparison to day $20(P=0.027)$, while that of $B 2 R$ decreased in days 40 and 60 as compared to day 20 $(P=0.0 I I)$; VEGF, Flt-I, KDR, B2R and eNOS expression showed no variations. Western blots for eNOS and Flt-I in placental homogenates showed no significant temporal differences along pregnancy.
\end{abstract}

Conclusion: The demonstration of different angiogenic, hyperpermeability and vasodilator factors in the same cellular protagonists of angiogenesis and invasion in the pregnant guinea-pig, supports the presence of a functional network, and strengthens the argument that this species provides an adequate model to understand human pregnancy. 


\section{Background}

The successful evolution of pregnancy requires finely tuned adaptations to permit an adequate exchange between fetal and maternal blood. On one hand, the fetal and maternal circulations establish close contact in the progressively extended and thin vascular structure of the placenta. On the other, utero-placental blood flow increases progressively, by transformation of the uterine arteries into large bore non-reactive vessels, achieved by cytotrophoblasts that disrupt the smooth muscle of the uterine arteries and replace their endothelium. Thus, both the angiogenic and invasive properties of the cytotrophoblast are critical in determining the fate of pregnancy [1-6].

Vascular endothelial growth factor (VEGF) seems to be fundamental to placentation. It is expressed in the uteroplacental interface of several species [7-13], in humans localizes mainly in the invading front of anchoring columns and in endovascular cytotrophoblasts, is down regulated in preeclampsia, and the blockade of its binding decreases cytotrophoblast expression of integrin $\alpha 1$, and increases apoptosis [14]; its removal from culture medium induces massive apoptosis of uterine microvascular endothelial cells [15]. Moreover, VEGF receptor knockout mice have a high embryonic lethality associated to defective angiogenesis [16,17]. VEGF could also increase vascular permeability in the endometrium, as demonstrated for tumoral cells [18]. Later, localized in perivascular trophoblasts, could through its vasodilator effect prime the uterine arteries for invasion, as has been suggested for NO [19], enhancing their high blood flow.

The pluripotential effects of VEGF are exerted by the activation of its two receptors, Flt-1 and KDR [20,21]. Of these, KDR can be the sole mediator of the physiological and pathological effects of VEGF, being capable of promoting angiogenesis and hyperpermeability in vivo. Flt-1 modulates KDR, preventing the excessive and disorganized formation of endothelial cells, promotes migration of endothelial cells, and upregulates the expression of MMP-9 [22]. In humans VEGF receptors are expressed in anchoring columns, are upregulated within their first cell layers and downregulated in severe preeclampsia and in the hemolysis, elevated liver enzymes and low platelet (HELLP) syndrome. In vitro inhibition of ligand binding to these receptors decreases cytotrophoblast invasion [14]. Both Flt-1 and KDR trigger a cascade that activates eNOS, via phosphatidilinositol 3-kinase and phospholipase $C \gamma 1$ respectively $[20,23,24]$ (Figure 1 ). The release of $\mathrm{NO}$, considered a second messenger for VEGF-driven angiogenesis with its consequent vasodilation, represent initiating events in sprouting angiogenesis [21].
Bradykinin is also a potent stimulus of eNOS, and NO production, through $\mathrm{Ca} 2+$ mediated mechanisms. Depending on the cell types, it can induce proliferative or antiproliferative effects, and appears to be an important agent in ischemia-induced angiogenesis [25]. The two cognate receptors of the kallikrein-kinin system are the type- 1 and type- 2 receptors (B1R and B2R), being the B2R ubiquitous and the main receptor of the classical effects of kinins (vasodilation, hyperpermeability), in contrast to the $\mathrm{B} 1 \mathrm{R}$, which is involved in tissue injury, reaction to cytokines or microbial products. The effects of VEGF are also enhanced by bradykinin [26,27].

The present study aims at demonstrating the localization and the variations in the expression of VEGF, Flt-1, KDR, $\mathrm{B} 2 \mathrm{R}$ and eNOS along pregnancy in guinea-pigs. We hypothesize that the localization of these functionally interrelated factors supports a network of angiogenic, hyperpermeability and vasodilator factors (Fig. 1), that participates in placental angiogenesis and cytotrophoblast invasion.

The pregnant guinea-pig was used in this study as it shares with the human utero-placental interfase a series of similarities, as a hemomonochorial structure, a subplacenta that resembles the anchoring villi as a source of extravillous trophoblasts, a decidual invasion and a transformation of the uterine arteries into low resistance high flow vessels [28-30]. Apart from the morphofunctional similarities, this species helps to circumvent the ethical and technical constraints that hinder the sequential study of normal or deranged human pregnancy.

We describe the expression of VEGF, Flt-1, KDR, B2R and eNOS in the same cell types of the feto-maternal interface of the guinea-pig, the subplacenta, the interlobar and labyrinthine placenta, syncytial streamers, peri and intravascular cytotrophoblasts, and fetal and maternal endothelial cells. This study supports our hypothesis for a functional role of this angiogenic, hyperpermeability and vasodilator network.

\section{Methods}

Guinea-pigs (Pirbright white 600 g) were kept under controlled humidity, temperature, and a 12-hour light: dark cycle. The animals were fed with Xtravital Special Food for Cavies (Beaphar, Holland) and supplemented with ascorbic acid in the drinking water. Litter size varied from 2-5 fetuses. Females were examined daily, and when vaginal opening was observed they were caged with fertile males. The day in which a vaginal plug, or sperms were observed in vaginal smears, was defined as day one of pregnancy. The experiments were approved by the IRB, and conducted according to the Guide for the Care and Use of Laboratory Animals (National Research Council, USA). 


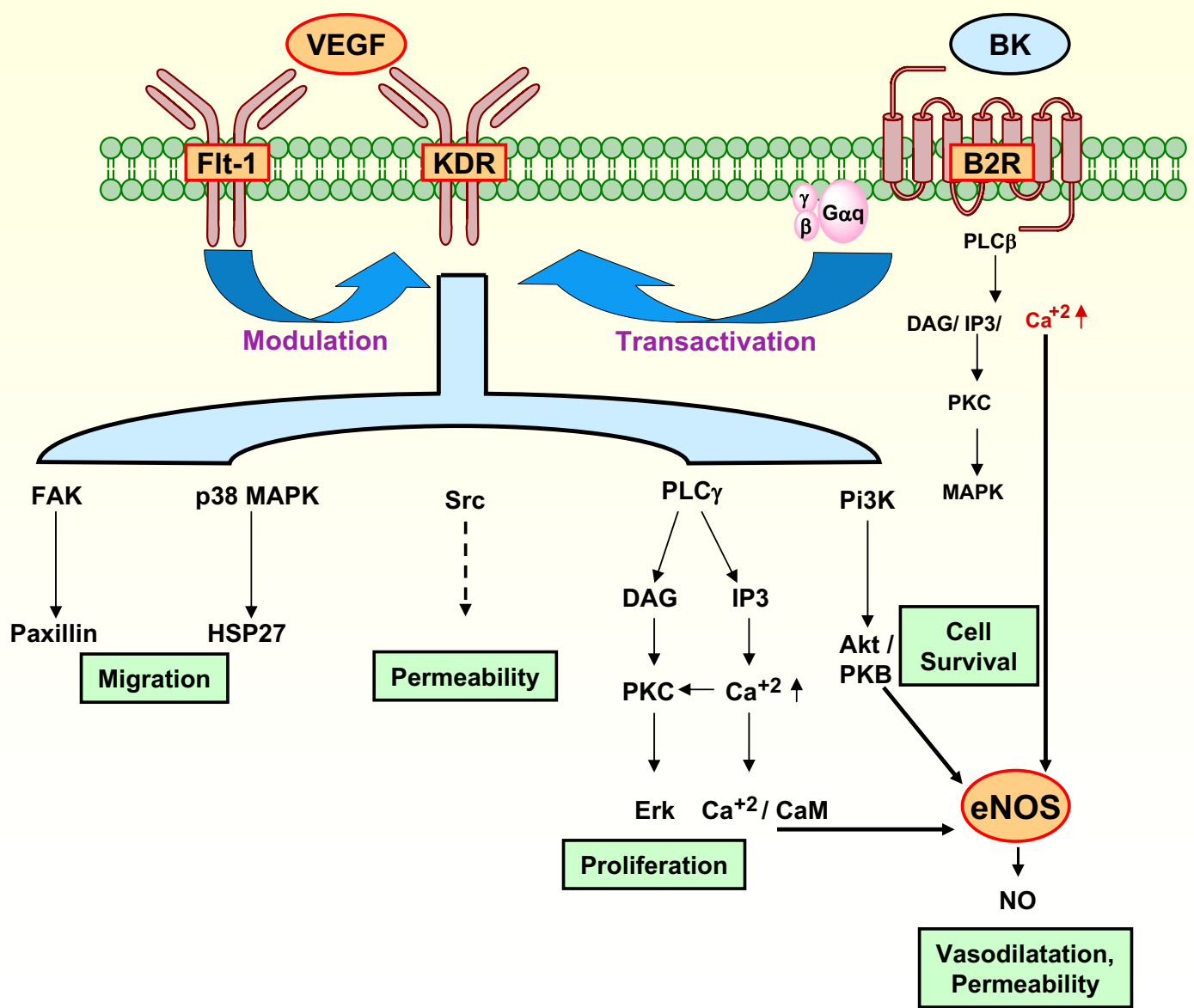

Figure I

Signaling pathways that contribute to VEGF induced angiogenesis, and a proposal for their participation in the development of the utero-placental interface by participating in proliferative, invasive, vasodilatory and permeability changes essential for cell invasion and angiogenesis. VEGF activates eNOS through pathways including Akt/ $\mathrm{PKB}, \mathrm{Ca}+2 / \mathrm{CaM}$, and PKC [20-24]. Flt-I may negatively regulate KDR, but might also promote its activity [20]. Bradykinin stimulates eNOS through $\mathrm{Ca}^{+2}$, induces EC to form tubes, and transactivates the KDR [26]. The factors studied have been depicted in orange areas surrounded by a red border, known mechanisms of downstream activation by interrupted arrows, and unknown mechanism of downstream activation by interrupted arrow. VEGF, vascular endothelial growth factor; BK, bradykinin; eNOS, endothelial nitric oxide synthase; PLC $\beta$, phospholipase C - $\beta$; PLC $\gamma$, phospholipase C - $\gamma$; DAG, diacylglycerol; IP3, inositol ( I,4,5)-triphosphate; PKC, protein kinase C; MAPK, mitogen-activated protein kinase; FAK, focal adhesion kinase; PI3K, phosphoinositide 3-kinase; p38 MAPK, p38 mitogen-activated protein; Erk, extracellular regulated kinase; HSP27, heat protein; CaM, calmodulin; EC, endothelial cell.

The animals were deeply anesthetized with a mixture of ketamine $(100 \mathrm{mg} / \mathrm{kg})$ and xylazine $(4 \mathrm{mg} / \mathrm{kg})$ given intraperitoneally. Twenty dams were sacrificed in early $(15,20$ days), mid $(30,45$ days $)$ and term (60 days) pregnancy ( $\approx$ length of pregnancy in the guinea-pig 63 days). The uterus and feto-placental units were removed; in some units a central slice through the placenta, subplacenta, implantation site and underlying myometrium was fixed as a single block; in other units, the placenta, endometrium, and mesometrium were separately dissected. The animals were euthanized with an overdose of anesthetic. Tissues were fixed immediately with phosphate-buffered $4 \%$ formalin for $24 \mathrm{~h}$. The fixed tissues were dehydrated in a graded series of ethanol and xylene, and embedded in Paraplast-Plus ${ }^{\circledR}$ (Sigma, St. Louis, MO). Serial sections $(5 \mu \mathrm{m})$ were mounted on silanized slides.

\section{Immunostaining procedure}

All immunostaining procedures were performed at room temperature; deparaffinized sections were rehydrated through ethanol and methanol, rinsed three times for five minutes in PBS-50 mM Tris- $\mathrm{HCl}$ pH 7.8 and submitted to 
heat antigen retrieval using citrate buffer $\mathrm{pH} 6.0$ for eNOS, VEGF, Flt- 1 and KDR, cytokeratin and von Willebrand factor, and Tris-HCl-EDTA pH 9.0 for muscle actin and cytokeratin-7. Endogenous peroxidases were blocked by incubating in $10 \% \mathrm{H}_{2} \mathrm{O}_{2}$ for 20 minutes. Sections were incubated in a humid chamber for 30 minutes with protein block (Cas-Block ${ }^{\circledR}$, Zymed, San Francisco, CA) followed by incubation for $18 \mathrm{~h}$ at $4{ }^{\circ} \mathrm{C}$ with the primary antibodies: mouse monoclonal anti-eNOS (1:50, clone 3 BD Transduction Laboratories), VEGF (1:50, clone JH 121, Upstate); rabbit polyclonal KDR (1:500, Upstate) and Flt-1 (1:1000, Santa Cruz Biotechnology, Inc). The B2R antibody (1:4000), mixture of 8 polyclonal rabbit antisera that recognizes the various domains of the receptor, was raised against the rat kinin B2R, and was kindly donated by Dr. Werner Müller-Esterl, Frankfurt Universitäts, Germany [31].

Sections were immunostained using a biotin-streptavidinperoxidase system (DakoCytomation, Carpinteria, CA). Finally, the samples were incubated for 15 minutes with $0.1 \%(\mathrm{w} / \mathrm{v}) 3-3^{\prime}$-diaminobenzidine in buffer containing $0.05 \% \mathrm{H}_{2} \mathrm{O}_{2}$. The slides were counterstained with Harris hematoxylin (Sigma, St. Louis, MO).

Cytotrophoblasts were identified by staining with an antipancytokeratin mouse monoclonal antibody (1:100, P2871, Sigma, St. Louis, MO), and in addition by cytokeratin 7-specific antibody (1:10, Clone OV-TL/12/30 DakoCytomation) that binds to all trophoblast populations and epithelial cells, and displays no reactivity for mesenchymal cells [32]. Smooth muscle and endothelial cells were characterized with antibodies against muscle actin (clone HHF35, 1:1000) and von Willebrand factor (A0082, 1:400) both obtained from DakoCytomation. The specificity of the staining was determined by incubation of sections in the absence of the first antibody, or in the presence of rabbit IgG fraction (1:100 and 1:4000) and mouse IgG serum (1:50), both from Dako Cytomation.

\section{Digital image analysis}

The immunostained sections of the placenta and endometrium were photographed with a Nikon CoolPix 4500 camera (Nikon Inc., Tokyo, Japan) coupled to a Zeiss AxioImager AX.10 microscope (Carl Zeiss, CA) using a $20 \times$ and $40 \times$ objectives [33].

The immunohistochemical expression of VEGF, Ft1-1, $\mathrm{KDR}$, eNOS and B2R was digitally analyzed in a total of fifteen fields from each placenta and endometrium, which were photographed from five sections per dam, in three animals in each of the following periods: early (20 days), mid (40 days) and term (60 days) pregnancy. The images were loaded into the Image v.1.34 software (National
Institutes of Health, Bethesda, MD) for analysis. A total of 243 syncytial streamers were manually delineated, extracted from the surrounding tissue to a separate image file and saved in JPEG format. Immunoreactive signals were extracted from the images with a color deconvolution algorithm [34], integrated in the ImageJ software. After conversion of pixel luminosity values to an optical density scale, the integrated optical density was measured in the previously extracted positive staining images and normalized by the positive area in each microphotograph. The signal intensity (I) was calculated as $\mathrm{I}=10 \cdot \sum \mathrm{OD} / \mathrm{A}$ in $\mathrm{dB} / \mu \mathrm{m}^{2}$, being $\Sigma$ OD the integrated optical density, and $\mathrm{A}$ the area of positive staining $\left(\mu \mathrm{m}^{2}\right)$ [35].

\section{Protein extraction}

Total proteins from placenta from early, mid and term pregnancy were extracted using $5 \mathrm{ml} / \mathrm{g}$ of $20 \mathrm{mM}$ Tris- $\mathrm{HCl}$ buffer containing $10 \mathrm{mM}$ EDTA, $2 \mathrm{mM}$ phenylmethylsulfonylfluoride, $5 \mu \mathrm{M}$ leupeptin, $50 \mu \mathrm{g} / \mathrm{ml}$ soybean trypsin inhibitor, $0.05 \%$ Brij-35 and $0.02 \% \mathrm{NaN}_{3}$ at $\mathrm{pH} 7.4$. Tissues were homogenized with a Tekmar Tissumizer (Cincinnati, $\mathrm{OH}$ ) for one minute on ice. Crude homogenates were centrifuged at $4000 \mathrm{rpm}$ for 20 minutes, then $0.2 \%$ SDS was added to the supernatant, kept for 1 hour at $4^{\circ} \mathrm{C}$, centrifuged at $14000 \mathrm{rpm}$ for $20 \mathrm{~min}$ at $4^{\circ} \mathrm{C}$ and finally stored at $-70^{\circ} \mathrm{C}$. Protein content was determined according to the Lowry method [36].

\section{Western blot analysis}

Equal amounts of protein $(100 \mu \mathrm{g} /$ lane $)$ were separated using 10\% SDS-PAGE under reducing conditions and transferred to nitrocellulose membranes (Biorad, Hercules, CA), blocked with 3\% nonfat dry milk in PBS- $0.1 \%$ Tween-20 buffer (PBS-T) and incubated overnight at $4{ }^{\circ} \mathrm{C}$ with the same primary antibodies used in immunohistochemistry: mouse monoclonal anti-eNOS (1: 1000, clone 3 BD Transduction Laboratories) and rabbit polyclonal Flt-1 (1: 200, Santa Cruz Biotechnology, Inc) diluted in blocking buffer.

The membranes were washed three times for five minutes in PBS-T buffer, incubated with HRP-conjugated antimouse or anti-rabbit secondary antibodies (both 1:3000, Biorad, Hercules, CA) for one hour at room temperature and developed with chemiluminescence reagent (NEL103, Western Lighting, Perkin-Elmer, MA) [36,37]. Membranes were exposed to CL-xPosure film (Pierce, Rockford, IL). Equal protein loading (100 ug/lane) was confirmed with Ponceau-S red staining (Sigma, St. Louis, $\mathrm{MO})$. Images were scanned at 16-bit/600 dpi resolution with an Epson Perfection 3490 scanner (Epson Corporation, CA), saved as tiff files and calibrated to an optical density scale. The integrated optical density of bands was quantitated using the ImageJ v.1.34 software. 
Purified human Flt-1 and eNOS yielded bands with approximate molecular weights of 180 and $140 \mathrm{kDa}$ respectively $[38,39]$.

\section{Statistical analysis}

Overall differences between the three studied periods of pregnancy were assessed with SPSS v 10 (SPSS Inc., Chicago, IL) using the one-way analysis of variance and Tukey's Multiple Comparison post-hoc test. $\mathrm{P}<0.05$ was chosen as significance level for all analyses performed. Results are expressed as means \pm SEM.

\section{Results}

Spatio-temporal expression of VEGF, Flt-1, KDR, B2R and eNOS in utero-placental units.

\section{Subplacenta}

The plied multilayered subplacenta represented the main, if not the exclusive, source of trophoblasts, as syncytial sprouts could be observed as early as day 15 of gestation emerging from its abluminal side to penetrate the first inner third of the endometrium. In addition, syncytiotrophoblast buds, emerging from the luminal side, constituted the earliest expression of the subplacenta. At this early stage, and throughout pregnancy, the subplacental syncytiotrophoblasts expressed granular immunoreactivity for VEGF, Flt-1, KDR, B2R and eNOS (Fig. 2).

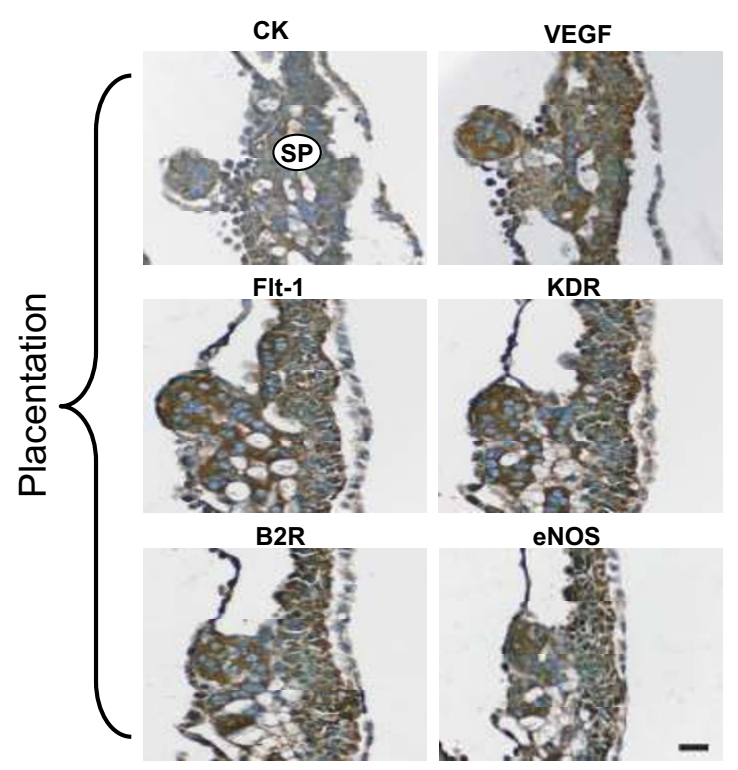

\section{Placenta}

From day 15 of pregnancy to term trabeculae and syncytiotrophoblast plates, originating from the subplacenta, expressed immunoreactivity for VEGF, Flt-1, KDR, B2R and eNOS, as granules in the thick bands of syncytiotrophoblast of the interlobium; in the labyrinth immunoreactivity for all factors displayed a diffuse reaction in the thin syncytial trabeculae and a thin lineal one in the endothelial cells. The cellular density of the interlobium showed a mild increase as pregnancy progressed, while that of the labyrinth increased markedly between days 40 and 60 as compared to day 20 (Fig. 3).

The digital quantification of the reactivity showed that in the interlobium Flt-1 increased in days 40 and 60 (10.4 \pm 0.62 and $10.2 \pm 0,23 \mathrm{~dB} / \mu \mathrm{m}^{2}$ respectively), as compared to day $20\left(8.3 \pm 0.10 \mathrm{~dB} / \mu \mathrm{m}^{2} ; \mathrm{P}=0.016\right)$, and in the labyrinth in day $60\left(10.6 \pm 0.32 \mathrm{~dB} / \mu \mathrm{m}^{2}\right)$, as compared to days 20 and $40\left(7.9 \pm 0.83\right.$ and $10.0 \pm 0.20 \mathrm{~dB} / \mu \mathrm{m}^{2}$ respectively; $\mathrm{P}=0.026)$. VEGF showed no variations in the interlobium or labyrinth (Fig. 3). KDR, B2R, and eNOS (not shown) displayed no changes. Western blots of placental homogenates showed no significant differences for Flt-1 and eNOS (Fig. 4).

\section{Endometrium}

As early as day 15 of gestation, VEGF in cytokeratin positive cells was expressed in pericytes, and in invasive tro-

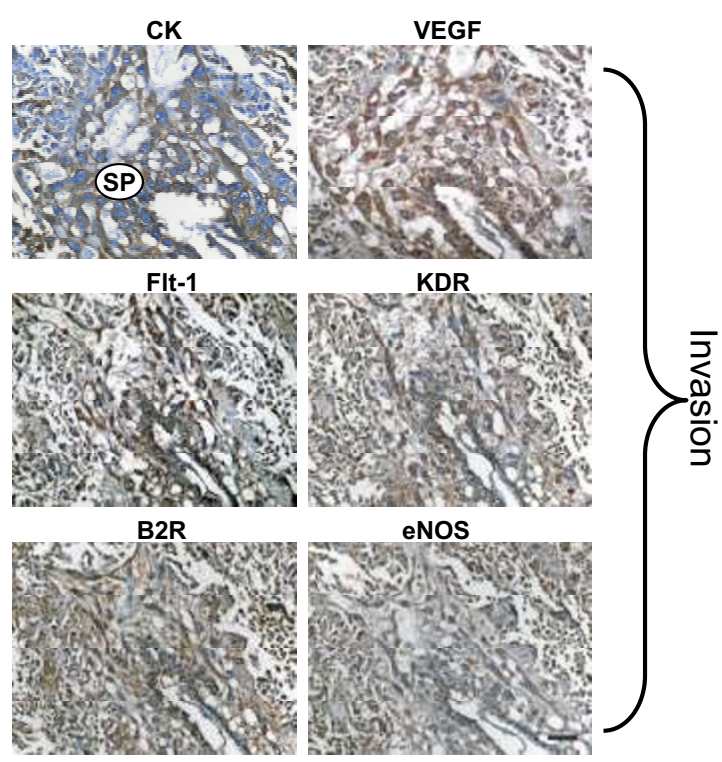

\section{Figure 2}

In subsequent sections of a utero-placental unit obtained in day 15 of pregnancy, the multilayered subplacenta (SP) gave rise to the placental sprouts, and to the syncytial streamers that penetrate the adjacent decidua. The subplacenta, the placental sprouts and the syncytial streamers expressed VEGF, Flt-I, KDR, B2R and eNOS. Cytotrophoblasts were characterized by cytokeratin (CK) staining. Bar $=100 \mu \mathrm{m}$. 

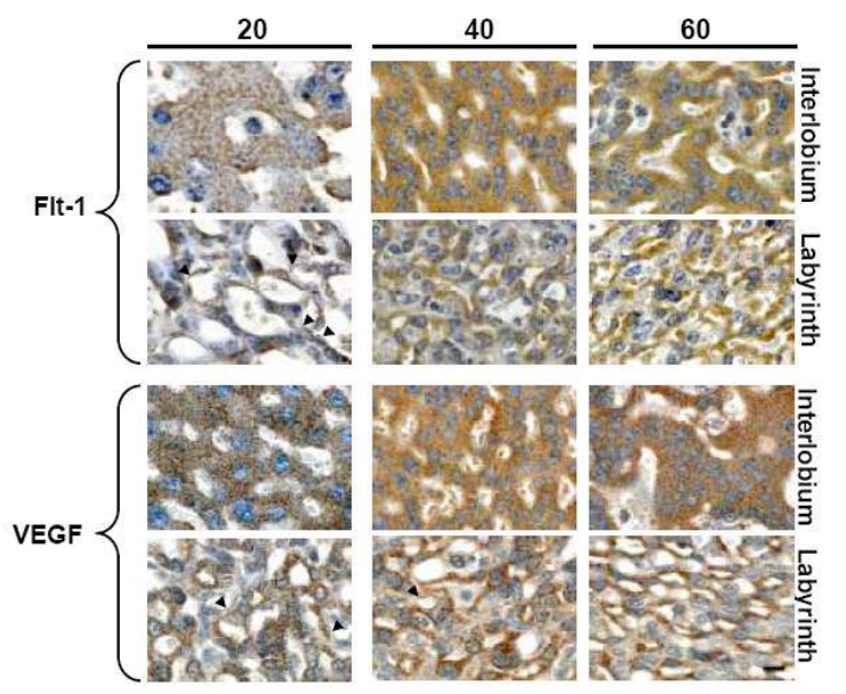

Figure 3

Syncytiotrophoblasts composing the interlobium and the labyrinth expressed FIt-I and VEGF, in sections obtained in days 20, 40 and 60 of pregnancy at a high magnification (1000x). The immunoreactivity showed a granular pattern for interlobar Flt-I, and for interlobar and labyrinthine VEGF; labyrinthine Flt-I displayed a diffuse cytoplasmic staining. Arrowheads highlight linear signal in endothelial cells. Bar $=100 \mu \mathrm{m}$.

phoblasts coalescing into syncytial streamers that migrated into the endometrium. Intraluminal plugs were observed in some arteries from day 20 onwards (not shown).

VEGF, Flt-1, KDR, B2R and eNOS immunoreactivity in syncytial streamers showed a granular staining (Fig. 5). Quantification by digital analysis showed an increased VEGF expression in day $40\left(10.1 \pm 0.8 \mathrm{~dB} / \mu \mathrm{m}^{2}\right)$ in com-

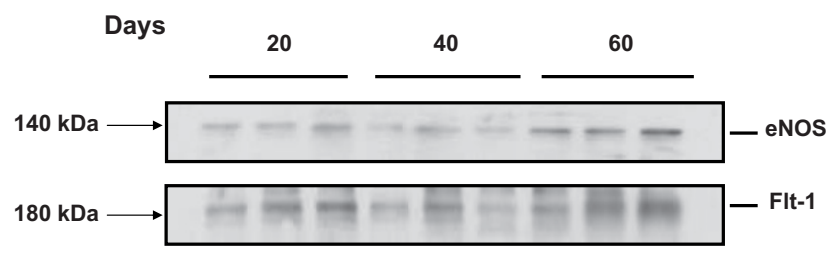

\section{Figure 4}

Representative blot of placental homogenates from days 20, 40 and $\mathbf{6 0}$ of pregnancy for FLT-I and eNOS. Purified human Flt-I and eNOS yielded bands with approximate molecular weights of 180 and $140 \mathrm{kDa}$ respectively. No significant differences were observed between the means of the 3 homogenates included in each study period, using oneway analysis of variance and Tukey's Multiple Comparison post-hoc test. parison to day $20\left(6.8 \pm 0.7 \mathrm{~dB} / \mu \mathrm{m}^{2} ; \mathrm{P}=0.027\right)$, while B2R decreased in days $40\left(7.3 \pm 0.4 \mathrm{~dB} / \mu \mathrm{m}^{2}\right)$ and $60(7.6$ $\left.\pm 0.1 \mathrm{~dB} / \mu \mathrm{m}^{2}\right)$ as compared to day $20\left(9.4 \pm 0.5 \mathrm{~dB} / \mu \mathrm{m}^{2}\right.$; $\mathrm{P}=0.011$ ); no differences were observed for Flt-1, KDR and eNOS.

Syncytial streamers were observed in the periphery of large decidual blood vessels near the subplacenta in mid and term pregnancy. In early pregnancy syncytial streamers were long thin projections of multinucleated trophoblasts. In mid pregnancy they formed thick and short aggregations, and in late pregnancy surrounded the arteries. Intramural cytotrophoblasts expressed all studied factors, as shown for VEGF and eNOS (Fig. 6).

\section{Myometrial and mesometrial arteries}

Myometrial arteries showed an intact thick (30 days) or a thin, partly disrupted ( 45 days) vascular smooth muscle layer, and were surrounded by cytotrophoblasts expressing VEGF. VEGF was also observed in swollen endothelial cells at 45 and 60 days. In late pregnancy cytotrophoblasts almost replaced the smooth muscle layer, attained the luminal border; and presented a granular staining for
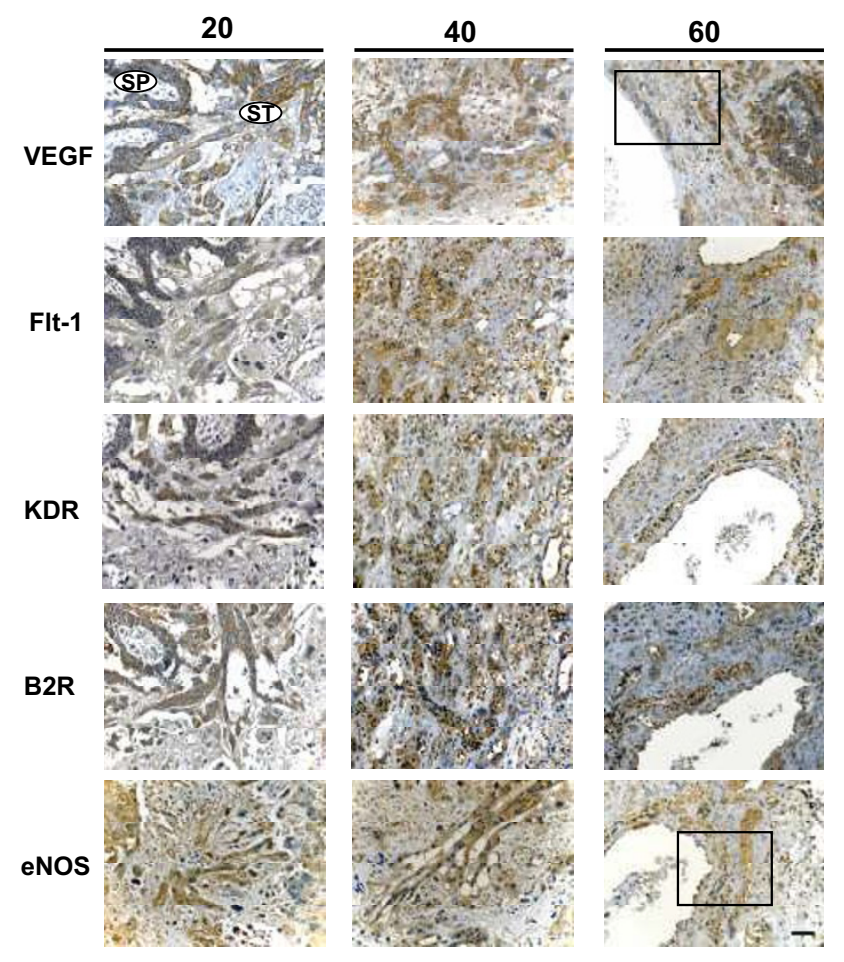

Figure 5

Syncytial streamers (ST) in the subplacenta (SP) and in the decidua expressed VEGF, FIt-I, KDR, B2R and eNOS in days 20, 40 and 60 of pregnancy. Bar $=100$ $\mu \mathrm{m}$. Rectangle defines the area shown at a higher magnification $(400 \times)$ in Figure 6. 
60
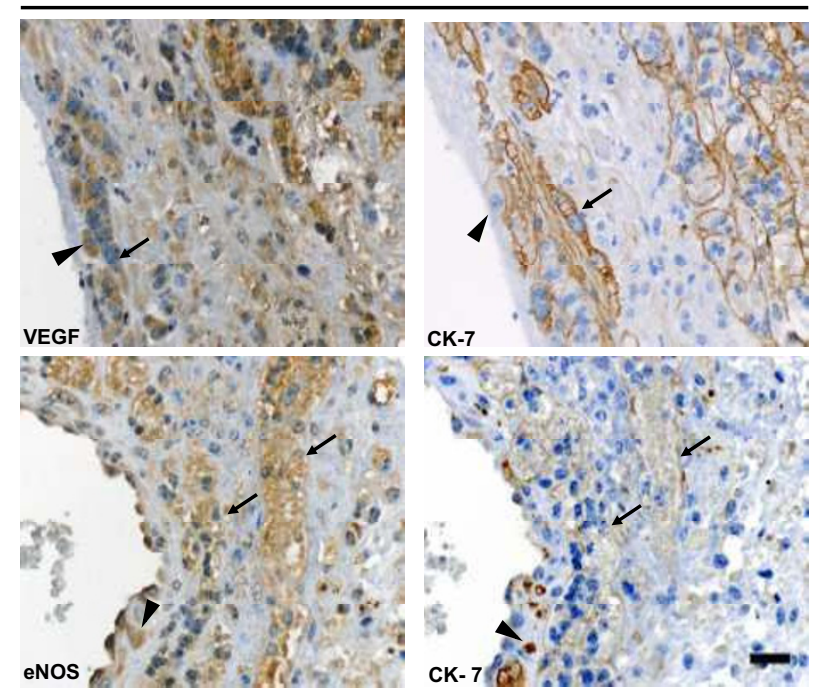

Figure 6

Syncytial streamers (arrows) in the vicinity of a decidual blood vessel in late pregnancy displayed granular VEGF and eNOS reactivity, and a linear pattern for cytokeratin-7 in the syncytial membrane. Intramural cytotrophoblasts (arrowheads) near the vessel lumen also expressed a granular eNOS reactivity, and intense intracytoplasmatic cytokeratin-7 staining. Bar $=100 \mu \mathrm{m}$.

VEGF (Fig. 7). Flt-1, KDR, eNOS and B2R had a similar expression than that of VEGF along the different stages of pregnancy (not shown).

Mesometrial arteries in early (20 days) and mid (40 days) pregnancy had a thick multilayer of smooth muscle cells and no trophoblasts were observed in their periphery or within the muscle layer. At term pregnancy (60 days) cytotrophoblasts replaced part of the muscle layer, and presented a positive signal for VEGF, Flt-1, KDR, B2R and eNOS. Swollen endothelial cells, identified by vWF, also expressed VEGF, Flt-1, KDR, B2R and eNOS (Figure 8). Control sections incubated with rabbit and mouse nonspecific immunoglobulin (Figure 9), or in absence of the first antibody (not shown), yielded no staining in different structures and stages of pregnancy.

\section{Discussion}

The present study provides the first demonstration that VEGF, its receptors Flt-1 and KDR, eNOS and the B2R, angiogenic, vasodilatory and hyperpermeability factors, are expressed in the same cell types of the guinea-pig fetomaternal interface along pregnancy. We postulate that these functionally interrelated factors represent a network that participates in placental angiogenesis and trophoblast invasion in an autocrine/paracrine way [1].

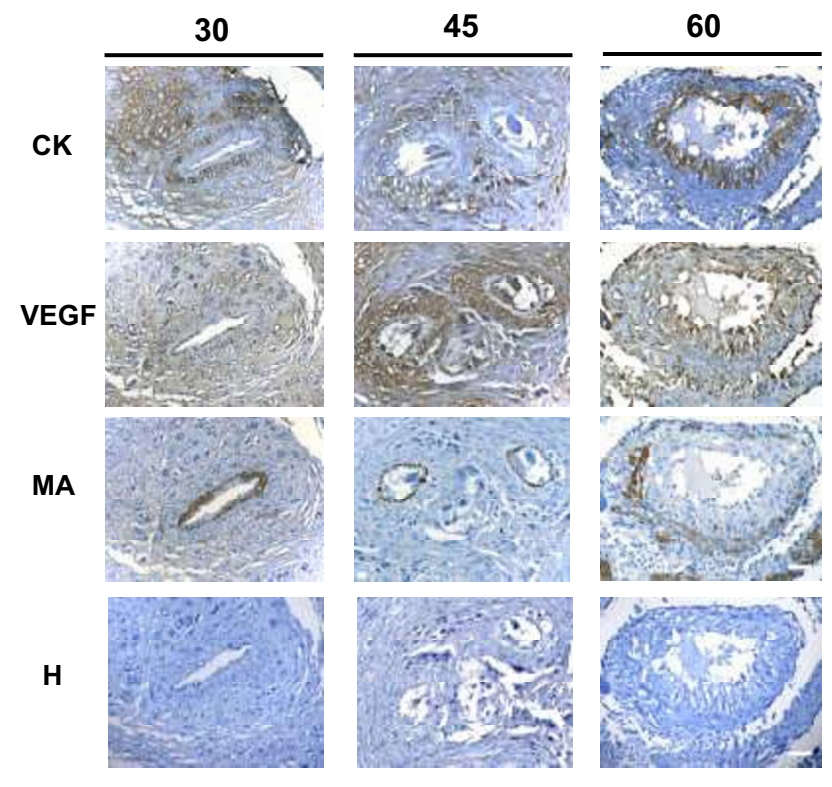

Figure 7

Spiral arteries observed in sequential sections of myometrium obtained in days 30, 45 and 60 of pregnancy. Cytokeratin positive trophoblasts expressed VEGF. The remaining vascular smooth muscle layers were positive for muscle actin (MA), and have been almost replaced in day 60. Bar $=100 \mu \mathrm{m}$.

We will now analyze the potential effect of these factors regarding the development and maintenance of the uteroplacental unit. The development of the placenta from endothelial cell precursors in the first syncytial buds requires enhanced vascular permeability, a consistent feature of angiogenesis; leaky vessels extravasate fibrinogen and plasminogen, which clotting into crosslinked fibrin and plasmin respectively, could favor endothelial cell adhesion and migration, as for tumoral cells [18]. Plasmin could activate MMPs, and in addition to kallikrein also present in utero-placental units in guinea-pigs [33], could participate in basement membrane degradation. Once the placenta is developed, the anticoagulating effect of $\mathrm{NO}$ and bradykinin could prevent platelet aggregation in its intricate vascular spaces, favorable targets for platelet aggregation.

In the attachment and implantation stages, the increased vasodilatation of uterine blood vessels in the implantation sites probably increases blood flow to meet the demands of oxygen and nutrients of the embryo, prior to the development of the placental bed. It seems feasible that subplacental VEGF, bradykinin, and NO could generate edema, a prominent feature of decidualization, and jointly with changes in extracellular matrix could facilitate 
20
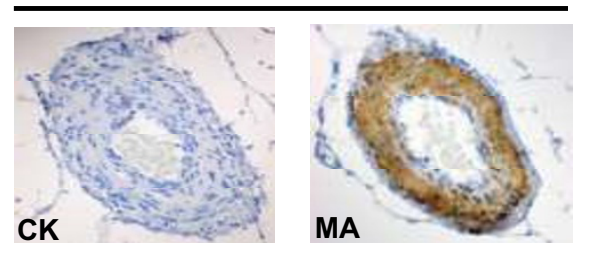

40

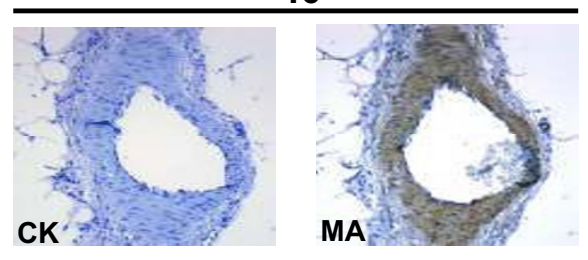

60
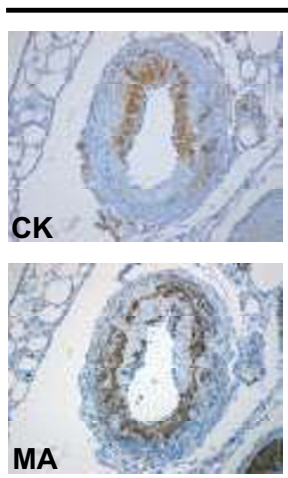
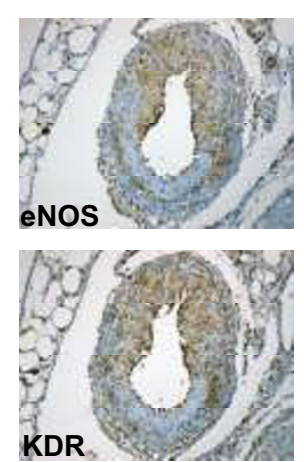
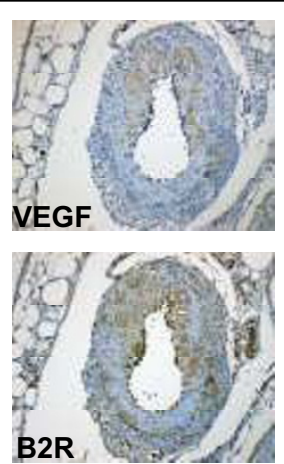
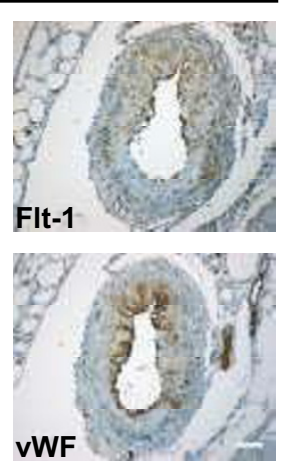

\section{Figure 8}

Mesometrial arteries obtained in days 20 and 40 of pregnancy showed in sequential sections an intact smooth muscle layer characterized by muscle actin (MA), and no cytokeratin positive cells. In day 60, intramural trophoblasts, characterized by cytokeratin (CK), expressed VEGF, Flt-I, KDR, B2R and eNOS, as did the swollen endothelial cells, identified by von Willebrand Factor ( $v W F)$. The remaining vascular smooth muscle, positive for muscle actin (MA), was disrupted. Bar $=100 \mu \mathrm{m}$.

trophoblast penetration of the underlying endometrium. The subsequent propagation of syncytial streamers could convey these effects to the deeper decidua, to finally facilitate disruption of the arterial wall. In the vicinity of uterine arteries these factors could prime the maternal vessels for invasion by relaxing smooth muscle cells and increasing arterial compliance, as proposed by Nanaev and cols[19].

Our observations on the localization of eNOS extend those of Nanaev and cols. who described positive eNOS extravillous trophoblasts extending from the junctional zone into the myometrium, as well as in those surrounding mesometrial arteries and replacing endothelial cells. Our finding of VEGF, eNOS and B2R in syncytial streamers supports a similar role in priming of spiral arteries. In comparison from a recent studies of Kaufmann and cols., and Bosco and cols., we were unable to recognize the isolated invasive extravillous trophoblasts described in the transitional zone lateral to the subplacenta of the guineapig and degu $[30,40]$. These trophoblasts are reported to be cytokeratin negative while traversing the endometrium, and thus are hard to identify; we postulate that these are later represented by intramural cytotro- phoblasts, which having switched their phenotype are able to express cytokeratin and the panel of factors here studied.

Several factors may be responsible for the discrepancy between the significant temporal variations observed in immunohistochemistry and the absence of changes observed in western blotting. First, the inherent differences of both techniques; while immunohistochemistry depends on the exposition of the epitopes, thus on the conformation of the protein, western blotting depends on its solubility and integrity along the stages of homogenization. However, both methods complement each other; while placental homogenates including interlobium and labyrinth demostrated proteins with the equivalent weights of Flt-1 and eNOS, the immunohistochemistry determined the protein expression in each of the different zones. Though the discrepant findings between both methods pose the need to pursue the characterization of the temporal variations, the immmunohistochemistry suggests an upregulated expression of Flt- 1 in the interlobium in mid and late gestation and in the labyrinth near term, as well as of VEGF and the B2R in syncytial streamers in early and mid gestation. 

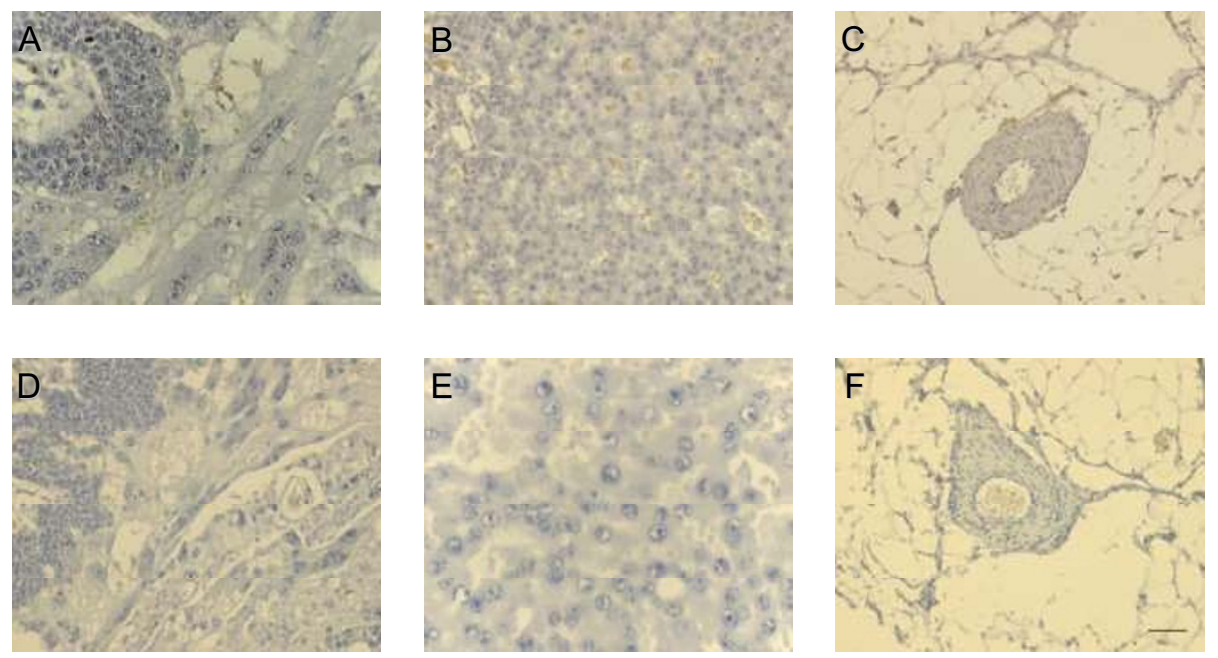

\section{Figure 9}

Control sections at different days of pregnancy of the subplacenta and syncytial streamers (A, D), interlobium $(B, E)$ and mesometrial arteries (C, F), which yielded no immunoreactivity incubated with non-specific IgG from mouse $(I: 50)$ and rabbit $(I: 100)$, species in which the antibodies were raised. Mouse IgG serum in $(A, B, C)$ and rabbit lgG fraction in (D, E, F). Bar $=100 \mu \mathrm{m}$

In vivo and in vitro studies in the guinea-pig need to be done to evaluate the individual importance of the factors here described. The alterations induced by interfering with VEGF through the soluble form of Flt-1 (sFlt-1) $[41,42]$, the decrease in cytotrophoblast invasion and expression of integrin $\alpha 1[14]$ and the increased apoptosis by inhibition of the ligand binding of VEGF have proven the functional relevance of its pathway. The importance of the nitridergic system has been confirmed by the blockade of eNOS with L-NAME [43-45]. Alterations in pregnancy in Brown Norway rats [46], a strain with a defective kallikrein-kinin system [47], and the high predictive index of preeclampsia of low urinary kallikrein in early human pregnancy [48], suggest that a deficient kallikrein-kinin system may hinder the local adaptations of pregnancy, thus its functional role deserves to be elucidated.

In humans, immunoreactive VEGF, Flt-1, KDR $[8,49]$ and eNOS [50-55] have been detected in villous cyto and syncytiotrophoblasts, fetal capillaries, and in extravillous trophoblasts; moreover, the B2R has been described in these cell types, and in addition in intraarterial trophoblasts [51]. The localization of these factors in placental syncytiotrophoblasts, fetal endothelial cells, and invading trophoblasts in the guinea-pig, bears a concordance with that described for cell types that in the human morphologically and functionally resemble the placental syncytium and endothelium, and the invasive trophoblasts.

\section{Conclusion}

The expression of angiogenic, permeability enhancers and vasodilatory factors in the human and guinea-pig uteroplacental interface supports for them complex, and perhaps redundant, interrelated functional roles. Moreover, this study underscores the importance of the model of the pregnant guinea-pig to understand human pregnancy.

\section{Competing interests}

The author(s) declare that they have no competing interests.

\section{Authors' contributions}

The study design, the histological analysis, the interpretation of the data and the drafting of the manuscript were done by JC and GV, the animals were sacrificed by JC, RE and CC; the immunohistochemistry was performed by JC, $\mathrm{RE}$ and $\mathrm{CC}$, western blots, image and densitometrical analysis were done by RE. All authors read and approved the final manuscript.

\section{Acknowledgements}

In recognition to Professor Peter Kaufmann for his seminal work in placentation, and for providing the foundations for the study of pregnancy in the guinea-pig.

This study has been supported by grant Fondecyt 1050707.

\section{References}

I. Charnock-Jones DS, Kaufmann P, Mayhew TM: Aspects of human fetoplacental vasculogenesis and angiogenesis. I. Molecular regulation. Placenta 2004, 25:103-II3. 
2. Kaufmann P, Black S, Huppertz B: Endovascular trophoblast invasion: implications for the pathogenesis of intrauterine growth retardation and preeclampsia. Biol Reprod 2003, 69: I-7. 3. Kaufmann P, Mayhew TM, Charnock-Jones DS: Aspects of human fetoplacental vasculogenesis and angiogenesis. II. Changes during normal pregnancy. Placenta 2004, 25: I |4- 26.

4. Kingdom J, Huppertz B, Seaward G, Kaufmann P: Development of the placental villous tree and its consequences for fetal growth. Eur J Obstet Gynecol Reprod Biol 2000, 92:35-43.

5. Mayhew TM, Charnock-Jones DS, Kaufmann P: Aspects of human fetoplacental vasculogenesis and angiogenesis. III. Changes in complicated pregnancies. Placenta 2004, 25:127-139.

6. Reynolds LP, Redmer DA: Angiogenesis in the placenta. Biol Reprod 2001, 64:1033-1040.

7. Bogic LV, Brace RA, Cheung CY: Developmental expression of vascular endothelial growth factor (VEGF) receptors and VEGF binding in ovine placenta and fetal membranes. Placenta 200I, 22:265-275.

8. Clark DE, Smith SK, Sharkey AM, Charnock-Jones DS: Localization of VEGF and expression of its receptors flt and KDR in human placenta throughout pregnancy. Hum Reprod 1996, I I:1090-1098.

9. Pfarrer CD, Ruziwa SD, Winther $H$, Callesen $H$, Leiser R, Schams D, Dantzer $V$ : Localization of vascular endothelial growth factor (VEGF) and its receptors VEGFR-I and VEGFR-2 in bovine placentomes from implantation until term. Placenta 2006, 27:889-898.

10. Winther H, Dantzer V: Co-localization of vascular endothelial growth factor and its two receptors flt-I and kdr in the mink placenta. Placenta 200I, 22:457-465.

II. Wulff C, Wilson H, Dickson SE, Wiegand SJ, Fraser HM: Hemochorial placentation in the primate: expression of vascular endothelial growth factor, angiopoietins, and their receptors throughout pregnancy. Biol Reprod 2002, 66:802-8I2

12. Borowicz PP, Arnold DR, Johnson ML, Grazul-Bilska AT, Redmer DA, Reynolds LP: Placental growth throughout the last two thirds of pregnancy in sheep: vascular development and angiogenic factor expression. Biol Reprod 2007, 76:259-267.

13. Winther H, Ahmed A, Dantzer V: Immunohistochemical localization of vascular endothelial growth factor (VEGF) and its two specific receptors, FIt-I and KDR, in the porcine placenta and non-pregnant uterus. Placenta 1999, 20:35-43.

14. Zhou Y, McMaster M, Woo K, Janatpour M, Perry J, Karpanen T, Alitalo K, Damsky, Fisher SJ: Vascular endothelial growth factor ligands and receptors that regulate human cytotrophoblast survival are dysregulated in severe preeclampsia and hemolysis, elevated liver enzymes, and low platelets syndrome. Am J Pathol 2002, 160:1405-1423.

15. Zhou Y, Bellingard V, Feng KT, McMaster M, Fisher SJ: Human cytotrophoblasts promote endothelial survival and vascular remodeling through secretion of Ang2, PIGF, and VEGF-C. Dev Biol 2003, 263: I 14-125.

16. Fong GH, Rossant J, Gertsenstein M, Breitman ML: Role of the FltI receptor tyrosine kinase in regulating the assembly of vascular endothelium. Nature 1995, 376:66-70.

17. Shalaby F, Rossant J, Yamaguchi TP, Gertsenstein M, Wu XF, Breitman ML, Schuh AC: Failure of blood-island formation and vasculogenesis in Flk-I-deficient mice. Nature 1995, 376:62-66.

18. Dvorak HF, Brown LF, Detmar M, Dvorak AM: Vascular permeability factor/vascular endothelial growth factor, microvascular hyperpermeability, and angiogenesis. Am J Pathol 1995, 146:1029-1039.

19. Nanaev A, Chwalisz K, Frank HG, Kohnen G, Hegele-Hartung C, Kaufmann P: Physiological dilation of uteroplacental arteries in the guinea pig depends on nitric oxide synthase activity of extravillous trophoblast. Cell Tissue Res 1995, 282:407-42I.

20. Olsson AK, Dimberg A, Kreuger J, Claesson-Welsh L: VEGF receptor signalling - in control of vascular function. Nat Rev Mol Cell Biol 2006, 7:359-371.

21. Rahimi N: Vascular endothelial growth factor receptors: molecular mechanisms of activation and therapeutic potentials. Exp Eye Res 2006, 83:1005-1016.

22. Wang $H$, Keiser JA: Vascular endothelial growth factor upregulates the expression of matrix metalloproteinases in vascular smooth muscle cells: role of flt-I. Circ Res 1998, 83:832-840.
23. Kimura $\mathrm{H}$, Esumi $\mathrm{H}$ : Reciprocal regulation between nitric oxide and vascular endothelial growth factor in angiogenesis. Acta Biochim Pol 2003, 50:49-59.

24. Cross MJ, Dixelius J, Matsumoto T, Claesson-Welsh L: VEGFreceptor signal transduction. Trends Biochem Sci 2003, 28:488-494.

25. Leeb-Lundberg LM, Marceau F, Muller-Esterl W, Pettibone DJ, Zuraw $B L$ : International union of pharmacology. XLV. Classification of the kinin receptor family: from molecular mechanisms to pathophysiological consequences. Pharmacol Rev 2005, 57:27-77.

26. Miura S, Matsuo Y, Saku K: Transactivation of KDR/Flk-I by the B2 receptor induces tube formation in human coronary endothelial cells. Hypertension 2003, 4I: I I I8-I I 23

27. Thuringer D, Maulon L, Frelin C: Rapid transactivation of the vascular endothelial growth factor receptor KDR/FIk-I by the bradykinin B2 receptor contributes to endothelial nitricoxide synthase activation in cardiac capillary endothelial cells. J Biol Chem 2002, 277:2028-2032.

28. Kaufmann P, Davidoff M: The guinea-pig placenta New York: SpringerVerlag; 1977.

29. Kaufmann P, Davidoff M: The guinea-pig placenta. Adv Anat Embryol Cell Biol |977, 53:5-91.

30. Mess A, Zaki N, Kadyrov M, Korr H, Kaufmann P: Caviomorph placentation as a model for trophoblast invasion. Placenta 2007. 28: $1234-1238$.

31. Abu Alla S, Quitterer U, Grigoriev S, Maidhof A, Haasemann M, Jarnagin K, Müller-Esterl W: Extracellular domains of the bradykinin B2 receptor involved in ligand binding and agonist sensing defined by anti-peptide antibodies. J Biol Chem 1996, 27I: $1748-1755$

32. Blaschitz A, Weiss U, Dohr G, Desoye G: Antibody reaction patterns in first trimester placenta: implications for trophoblast isolation and purity screening. Placenta 2000, $21: 733-74 \mathrm{I}$.

33. Corthorn J, Rey S, Chacon C, Valdes G: Spatio-temporal expression of MMP-2, MMP-9 and tissue kallikrein in uteroplacental units of the pregnant guinea-pig (Cavia porcellus). Reprod Biol Endocrinol 2007, 5:27.

34. Ruifrok AC, Johnston DA: Quantification of histochemical staining by color deconvolution. Anal Quant Cytol Histol 200I, 23:291-299.

35. Rey S, Corthorn J, Chacon C, Iturriaga R: Expression and immunolocalization of endothelin peptides and its receptors, ETA and ETB, in the carotid body exposed to chronic intermittent hypoxia. J Histochem Cytochem 2007, 55:167-174.

36. Lowry OH, Rosebrough NJ, Farr AL, Randall RJ: Protein measurement with the Folin phenol reagent. J Biol Chem 1951, 193:265-275.

37. Burnette WN: "Western blotting": electrophoretic transfer of proteins from sodium dodecyl sulfate - polyacrylamide gels to unmodified nitrocellulose and radiographic detection with antibody and radioiodinated protein A. Anal Biochem | 981, I | 2: 195-203.

38. Rajakumar A, Michael HM, Rajakumar PA, Shibata E, Hubel C, Karumanchi S, Thadhani R, Wolf M, Harger G, Markovic N: Extraplacental expression of vascular endothelial growth factor receptor-I, (FIt-I) and soluble Flt-I (sFlt-I), by peripheral blood mononuclear cells (PBMCs) in normotensive and preeclamptic pregnant women. Placenta 2005, 26:563-573.

39. SchiessI B, Mylonas I, Hantschmann P, Kuhn C, Schulze S, Kunze S, Friese K, Jeschke U: Expression of endothelial NO synthase, inducible NO synthase, and estrogen receptors alpha and beta in placental tissue of normal, preeclamptic, and intrauterine growth-restricted pregnancies. J Histochem Cytochem 2005, 53: | 44I-|449.

40. Bosco C, Buffet C, Bello MA, Rodrigo R, Gutierrez M, Garcia G: Placentation in the degu (Octodon degus): analogies with extrasubplacental trophoblast and human extravillous trophoblast. Comp Biochem Physiol A Mol Integr Physiol 2007, I 46:475-485.

4I. Levine RJ, Qian C, Maynard SE, Yu KF, Epstein FH, Karumanchi SA: Serum sFIt I concentration during preeclampsia and mid trimester blood pressure in healthy nulliparous women. $\mathrm{Am} J$ Obstet Gynecol 2006, 194:1034-104I.

42. Maynard SE, Min JY, Merchan J, Lim KH, Li J, Mondal S, Libermann TA, Morgan JP, Sellke FW, Stillman IE, Epstein FH, Sukhatme VP, 
Karumanchi SA: Excess placental soluble fms-like tyrosine kinase I (sFItI) may contribute to endothelial dysfunction, hypertension, and proteinuria in preeclampsia. J Clin Invest 2003, I I I :649-658.

43. Buhimschi I, Yallampalli C, Chwalisz K, Garfield RE: Pre-eclampsialike conditions produced by nitric oxide inhibition: effects of L-arginine, D-arginine and steroid hormones. Hum Reprod 1995, 10:2723-2730

44. Helmbrecht GD, Farhat MY, Lochbaum L, Brown HE, Yadgarova KT, Eglinton GS, Ramwell PW: L-arginine reverses the adverse pregnancy changes induced by nitric oxide synthase inhibition in the rat. Am J Obstet Gynecol 1996, I75:800-805.

45. Salas SP, Vuletin JF, Giacaman A, Rosso P, Vio CP: Long-term nitric oxide synthase inhibition in rat pregnancy reduces renal kallikrein. Hypertension 1999, 34:865-87I.

46. Konno T, Rempel LA, Arroyo JA, Soares MJ: Pregnancy in the brown Norway rat: a model for investigating the genetics of placentation. Biol Reprod 2007, 76:709-7/8.

47. Damas J, Adam A: The kallikrein-kininogens-kinins system in the Brown-Norway rat. Biomedicine 1979, 3 I:249.

48. Smith C, Campbell S, Albano J, Clark A, Millar G: Urinary kallikrein excretion in normotensive and hypertensive pregnancies: 8 years later. Immunopharmacology 1999, 44:177-I82.

49. Tseng JJ, Chou MM, Hsieh YT, Wen MC, Ho ES, Hsu SL: Differential expression of vascular endothelial growth factor, placenta growth factor and their receptors in placentae from pregnancies complicated by placenta accreta. Placenta 2006, 27:70-78.

50. Ariel I, Hochberg A, Shochina M: Endothelial nitric oxide synthase immunoreactivity in early gestation and in trophoblastic disease. I Clin Pathol 1998, 5 I:427-43 I.

51. Corthorn J, Germain AA, Chacon C, Rey S, Soto GX, Figueroa CD, Müller-Esterl W, Duarte I, Valdés G: Expression of kallikrein, bradykinin b2 receptor, and endothelial nitric oxide synthase in placenta in normal gestation, preeclampsia, and placenta accreta. Endocrine 2006, 29:49।-499.

52. Martin D, Conrad KP: Expression of endothelial nitric oxide synthase by extravillous trophoblast cells in the human placenta. Placenta 2000, 21:23-31.

53. Matsubara S, Takizawa T, Takayama T, Izumi A, Watanabe T, Sato I: Immuno-electron microscopic localization of endothelial nitric oxide synthase in human placental terminal villous trophoblasts-normal and pre-eclamptic pregnancy. Placento 200I, 22:782-786.

54. Myatt L, Eis AL, Brockman DE, Greer IA, Lyall F: Endothelial nitric oxide synthase in placental villous tissue from normal, preeclamptic and intrauterine growth restricted pregnancies. Hum Reprod 1997, 12:167-172.

55. Orange SJ, Painter D, Horvath J, Yu B, Trent R, Hennessy A: Placental endothelial nitric oxide synthase localization and expression in normal human pregnancy and pre-eclampsia. Clin Exp Pharmacol Physiol 2003, 30:376-38I.

\section{Publish with Bio Med Central and every scientist can read your work free of charge}

"BioMed Central will be the most significant development for disseminating the results of biomedical research in our lifetime. "

Sir Paul Nurse, Cancer Research UK

Your research papers will be:

- available free of charge to the entire biomedical community

- peer reviewed and published immediately upon acceptance

- cited in PubMed and archived on PubMed Central

- yours - you keep the copyright
BioMedcentral 